\title{
Growing positivity for water fluoridation in 'Twittersphere'
}

\section{Positivity on the topic of water fluoridation \\ is growing on \\ Twitter where \\ the number of \\ supporters has \\ grown from nil \\ to $19 \%$ in five \\ years. \\ By contrast, \\ Facebook is a}

platform where

opposition to water fluoridation has

remained constant.

These are among the conclusions drawn from a paper which compares identical studies analysing social media accounts on Twitter and Facebook. Carried out five years apart, in 2015 and 2021, the studies looked at the public's perception of water fluoridation as expressed on social media. Accounts were divided into three groups, supportive, anti or neutral to water fluoridation.

BFS member Rebecca Linney undertook the 2015 study as part of her dental degree to understand how social media was being used by campaigners. She was fascinated by the topic because she comes from Liverpool where the water is not fluoridated but undertook her dental degree in fluoridated Birmingham.

In March of this year Linney repeated the study to test whether there had been a change in perceptions. A key finding of her comparison is that today, $19 \%$ of Twitter accounts featuring water fluoridation support the public health measure whereas in 2015 there were no pro water fluoridation accounts at all.

It's a topic which invokes strong feelings, with libertarians opposing the view that fluoride should be added to drinking water supplies alongside other chemicals that prevent disease, such as chlorine, which protects from cholera and typhoid. This is counter to the view of most healthcare organisations, especially dental, which support all measures designed to improve health through universal measures.

Dr Linney's other key findings are:

$\rightarrow$ Facebook continues to be the platform where there is most negativity around water fluoridation

$\rightarrow$ The number of anti water fluoridation pages on Facebook has increased but the number of anti water fluoridation groups has decreased

$\rightarrow$ There are more pro-fluoridation events on Facebook

$\rightarrow$ Today there are fewer Twitter accounts which could be described as uncategorised or neutral in relation to water fluoridation.

Dr Linney said: 'I was particularly interested to see that there are more events supporting water fluoridation listed on Facebook, indicative of an upsurge of commitment to promoting water fluoridation.

'I can also see that there is now more support on Twitter thanks to the British Fluoridation Society, Public Health England, the Oral Health Foundation and many more organisations using their accounts to post informative statements and links.'

Barry Cockcroft, Chairman of British Fluoridation Society added: 'This paper is really useful in understanding how important it is to continue to communicate clear and scientific statements about water fluoridation. The fact is, unless we keep active on social media, opponents will fill that vacuum. This is a most valuable piece of work.'

\section{BSPD applauds oral health recognition in hospitals}

The British Society of Paediatric Dentistry (BSPD) has applauded the news that oral health of children in hospital is recognised as fundamental to their wellbeing thanks to The Mini Mouth Care Matters programme.
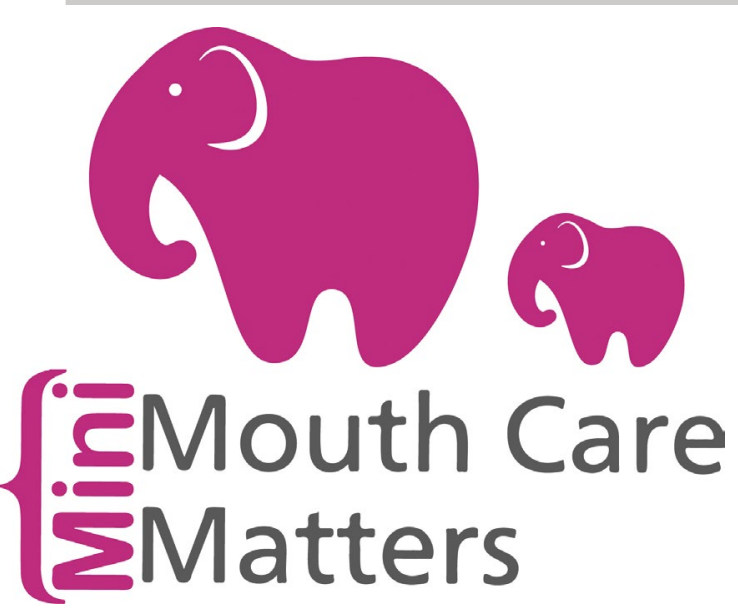

The programme, which is benefiting thousands of children throughout the UK, is the work of one of its members and national lead for Mini MCM, Dr Urshla Devalia.

Also a Consultant in Paediatric Dentistry, Dr Devalia began devising Mini Mouth Care Matters nearly three years ago. At the heart of the programme is training for ward staff in hospitals to ensure that young in-patients always benefit from an oral health check. Hospital teams are taught to 'lift-the-lip' so they have the confidence to look inside the mouth of young patients and understand any warning signs.

In addition to training, a range of resources, including an assessment tool, is made available to hospitalbased healthcare practitioners. The programme branding includes a little elephant by the name of
Elwood, a reminder to 'never forget' tooth brushing. Images of Elwood are now to be found in hospitals up and down the country beside the beds of paediatric patients, and also on posters and leaflets in hospital staff rooms and waiting areas.

Claire Stevens, BSPD's spokesperson commented: 'It's incredible to see the way in which this programme is not only embedded as routine in hospitals with paediatric wards but also that it's extending into other settings including the training of health visitors and hospice staff.

'The small adaptations in care delivered by Mini MCM can significantly improve the quality of life of this cohort of children and young people and also provide new knowledge and skills for healthcare practitioners who learn to 'lift the lip.' As an innovative and transferable programme, Mini MCM has outstripped its vision.' 